\title{
Pengelolaan sumberdaya ikan lema (Ratrelliger kanagurta) yang berbasis kearifan lokal di Kampung Warsamdin dan Lopintol, Distrik Teluk Mayalibit, Provinsi Papua Barat
} Management of mackerel (Ratrelliger kanagurta) resources based on local wisdom in the
villages of Warsamdin and Lopintol, Mayalibit Bay District, Province of West Papua

\author{
WAHALID NAJAMUDIN*, EMIL REPPIE dan LEFRAND MANOPPO \\ Program Studi Pemanfaatan Sumberdaya Perikanan, Fakultas Perikanan dan Ilmu Kelautan, \\ Universitas Sam Ratulangi, Manado 95115
}

\begin{abstract}
People in the villages of Lopintol and Warsamdin, Raja Ampat have local knowledge called lobe in managing mackerel resource (Rastrelliger kanagurta), which set the pattern of utilization and do not damage the ecosystem of coastal waters through a religious approach. The purpose of this research is to describe the local knowledge of Lopintol and Warsamdin villages communities in managing mackerel resources; to inventory and identify the type of goto used; and to determine the composition of catch length. This research was conducted in December 2014. Lobe is local knowledge about catching mackerel, which is attracted with light at night in the middle of the bay; directed to shore up into the goto, then captured with a scoop net. The amount goto in Lopintol village is 44 units and entirely made of stone; while in Warsamdin village is 24 units; where 14 units made of stone, 4 units made of board, and 6 units made of wood. The catch during the study (14 trips) is 12516 fish. The percentage of fish fork length of 20-20.9 cm was 7. 3\%, 21-21.9 cm (37.7\%), 22-22.9 cm (15,0\%), and fork length 23-23.9 was 39.9\%. The fish caught had generally already ever done spawning reproduction.
\end{abstract}

Keywords: mackerel, lobe wisdom, goto, Mayalibit Bay

\begin{abstract}
ABSTRAK
Masyarakat di Kampung Warsamdin dan Kampung Lopintol, Kabupaten Raja Ampat memiliki kearifan lokal yang disebut lobe dalam mengelola sumberdaya ikan lema (Rastrelliger kanagurta) dengan mengatur pola pemanfaatan serta tidak merusak ekosistem perairan pantai melalui pendekatan religius yang mereka anut. Tujuan penelitian adalah mendeskripsikan kearifan lokal masyarakat kampung Warsamdin dan Lopintol dalam mengelola sumberdaya ikan lema; mengidentifikasi jenis goto yang digunakan dan mengetahui komposisi ukuran panjang hasil tangkapan. Penelitian ini dilaksanakan pada bulan Desember 2014. Lobe merupakan pengetahuan lokal tentang penangkapan ikan kembung yang dikumpulkan dengan cahaya lampu pada malam hari di tengah teluk, kemudian digiring ke pantai sampai masuk ke dalam goto, kemudian ditangkap dengan serok. Jumlah goto yang ada di kampung Lopintol sebanyak 44 goto seluruhnya goto batu, sedangkan di kampung Warsamdin sebanyak 24 buah yang terdiri dari goto batu 14 unit, goto papan 4 unit dan goto kayu 6 unit. Hasil tangkapan selama penelitian (14 trip) berjumlah 12.516 ekor. Presentase panjang garpu ikan 20-20,9 cm sebanyak 7,3\%, 21-21,9 cm (37,7\%), 22-22,9 cm (15,0\%) dan 2323,9 cm sebanyak 39,9\%. Ikan-ikan yang tertangkap umumnya sudah pernah memijah.
\end{abstract}

Kata-kata kunci: ikan kembung, kearifan lobe, goto, Teluk Mayalibit,

\section{PENDAHULUAN*}

Kampung Warsamdin dan Kampung Lopintol, Distrik Teluk Mayalibit terletak di pesisir pantai

\footnotetext{
* Penulis untuk penyuratan; email:

wahalidnajamudin@yahoo.com
}

yang memiliki kearifan lobe dalam mengelola sumberdaya ikan lema (kembung, Rastrelliger kanagurta), di mana sebagian besar penduduknya bermata pencaharian sebagai nelayan. Kearifan lokal adalah pandangan hidup dan ilmu pengetahuan serta berbagai strategi kehidupan 
yang berwujud aktivitas yang dilakukan oleh masyarakat lokal dalam menjawab berbagai masalah dalam pemenuhan kebutuhan. Dalam bahasa asing sering juga dikonsepsikan sebagai kebijakan setempat (local wisdom) atau pengetahuan setempat (local knowledge) atau kecerdasan setempat (local genious) (Syafaat, 2008).

Kearifan masyarakat dalam berinteraksi dengan alam hanya menjadi kekuatan normatif yang mengatur pada tatanan komunitas lokal saja. Masyarakat di Kampung Warsamdin dan Kampung Lopintol, misalnya memiliki kearifan lobe dalam mengelola sumberdaya ikan lema dengan mengatur pola pemanfaatan serta tidak merusak ekosistem perairan pantai melalui pola pendekatan religius yang mereka anut.

Berdasarkan uraian di atas, maka diadakan penelitian tentang kearifan pengelolaan sumberdaya ikan lema di Teluk Mayalibit. Salah satu sumberdaya perikanan yang dihasilkan dari Teluk Mayalibit adalah ikan kembung, dan yang uniknya bahwa ikan tersebut hanya ditangkap dengan serok. Namun informasi ilmiah tentang pemanfaatan ikan kembung dengan serok di kawasan tersebut belum tersedia.

Penelitian ini bertujuan untuk:

1) Mendeskripsikan kearifan lokal masyarakat di sekitar Teluk Mayalibit,

(2) Mengidentifkasi jenis-jenis goto yang dipergunakan oleh nelayan di Teluk Mayalibit,

(3) Mengetahui komposisi ukuran panjang dan berat ikan hasil tangkapan.

\section{METODE PENELITIAN}

Penelitian ini dilakukan di perairan Teluk Mayalibit pada Kampung pantai Lopintol dan Kampung Warsandim Distrik Teluk Mayalibit, Kabupaten Raja Ampat. Sedangkan waktu pelaksanaannya berlangsung selama 3 bulan, yaitu mulai bulan Oktober sampai dengan bulan Desember 2014. Penelitian ini dikerjakan melalui survei yang didasarkan pada metode deskriptif (Nasir (1999). Teknik pengumpulan data dilakukan dengan cara wawancara, pengamatan langsung, partisipasi aktif dan pengisian daftar pertanyaan terstuktur. Data dianalisis dengan mendeskripsikan konstruksi alat tangkap dan alat bantu, serta proses penangkapan ikan kembung dengan serok dan adat istiadat yang mengaturnya; mendeskripsikan berbagai jenis goto yang digunakan sebagai lokasi penangkapan ikan kembung; dan menganalisis ukuran panjang ikan kembung yang tertangkap.

\section{HASIL DAN PEMBAHASAN}

\section{Sejarah lobe}

Lobe artinya adalah menangkap ikan dengan menggunakan bantuan cahaya lampu pada malam hari. Lobe ditujukan untuk berburu ikan lasi (Scromberoides sp.), kuwe atau bobara (Caranx $\mathrm{sp}$ ), ikan merah atau somasi (Lutjanus argentimaculatus), baracuda (Sphyraena sp) dengan menggunakan tombak atau kalawai dari atas perahu dengan bantuan lampu petromaks di bagian haluan. Kegiatan ini telah lama dilakukan oleh masyarakat yang mendiami pesisir Teluk Mayalibit terutama masyarakat Kampung Warsamdin dan Lopintol untuk memenuhi kebutuhan hidup sehari-hari maupun untuk dijual ke masyarakat sekitar teluk terutama untuk memenuhi permintaan masyarakat di Kabupaten Waisai.

Pada tanggal 25 April 1980 Bapak Yosep Ansan dan kedua anaknya sedang melakukan kegiatan lobe, tiba-tiba dikejutkan oleh keberadaan ikan kembung atau lema yang bergerombol mendekati cahaya lampu. Bapak Yosep langsung bereaksi dengan tombaknya, namun karena cahaya tersebar luas, maka mereka menutup bagian belakang lampu dengan kemeja, agar cahaya lampu terfokus di depan perahu dan perahu didayung menuju tepi pantai yang dangkal, kemudian ikan lema ditangkap dengan menggunakan tombak. Setelah selesai menangkap, Bapak Yosep beserta kedua anaknya pulang dengan membawah hasil tangkapan yang banyak, sehingga ia membagikan kepada sanak saudara maupun masyarakat di sekitar rumahnya. Peristiwa tersebut, menjadi pokok pembicaraan masyarakat di Kampung Warsamdin maupun Kampung Lopintol.

Masyarakat setempat mulai mengadakan uji coba penangkapan untuk memperoleh hasil tangkapan yang optimal; kemudian mereka mendiskusikan bersama-sama bagaimana caranya menangkap ikan lema secara efektif dan memberikan manfaat bagi masyarakat. Cara-cara inilah yang merupakan pengetahuan lokal masyarakat. Hal ini, sejalan dengan pernyataan Syafaat (2008). 
Seiring dengan berjalannya waktu, maka kegiatan lobe sudah tidak lagi menggunakan tombak dan diganti dengan lai-lai (serok). Lai-lai pada awalnya dipakai untuk menimba (menangkap) kasia (ebi) berupa udang kecil, penggunaan lai-lai tersebut tidak dimodifikasi lagi dan langsung digunakan dalam menimba ikan lema.

Sasi atau penutupan musim panen dikenal masyarakat pada kedua kampung tersebut; yaitu sasi darat dan sasi laut. Sasi darat adalah larangan panen buah-buahan seperti langsat, cimpedak, mangga dan durian. Sedangkan sasi laut adalah larangan menangkap ikan lema, teripang (Holoturidae sp), udang (Panilurus sp) dan siput laut (kerang mutiara). Penetapan dilakukan sasi apabila produksi ikan lema mengalami penurunan hasil tangkapan. Dalam kehidupan bermasyarakat di kedua kampung ada adat istiadat yang masih berlangsung; pada saat musim paceklik diadakan upacara adat dan masyarakat diwajibkan membawa nasi, kakes (kapur, siri dan pinang) dan rokok. Serta membawa sedakah berupa uang ke kotak amal yang ada di Mesjid bagi yang beragama Muslim dan persembahan di bawa ke Gereja bagi yang beragama Kristen.

Pengelolaan ikan lema ditetapkan melalui musyawarah bersama dan diperoleh kesepakatan bersama yang dituangkan dalam Peraturan Kampung No. 1 Tahun 2013 tentang tata cara pengelolaan dan pemanfaatan sumberdaya ikan lema. Aturan kegiatan lobe di Kampung Warsamdin dan Lopintol bekerjasama dengan Coservation International Indonesia (CII), menetapkan bahwa kegiatan lobe (sasi laut) tidak diijinkan pada bulan September, Oktober dan November (penutupan musim penangkapan). Selain itu ada juga sasi yang berlaku pada setiap minggu berjalan yaitu, malam Jumat dan malam Minggu, hal ini untuk menghargai pemeluk yang beragama Islam maupun Kristen.

\section{Labuhan (Goto)}

Labuhan atau goto adalah tempat penggiringan akhir ikan untuk ditangkap dengan serok. Goto ini biasanya dibuat di daerah pantai yang agak terjal, dengan susunan batu membentuk kolam kecil yang terbuka pada salah satu sisinya.

Karena kondisi topografi wilayah kepulauan dengan gugusan pulau yang relatif curam, sehingga nelayan membuat goto dari batu maupun kayu. Tidak diketahui dengan pasti siapa yang memulainya, namun ide awal pembuatan goto ini lahir ditengah masyarakat Kampung Lopintol dan kemudian sampai di Kampung Warsamdin.

Jumlah goto yang terdapat di Kampung Lopintol sebanyak 44 buah goto batu dengan jumlah nelayan 44 orang (setiap nelayan memiliki satu goto). Kampung Warsamdin memiliki 24 buah goto, dengan jumlah nelayan 10 orang. Material goto di kampung Warsamdin terdiri dari goto batu 14 buah, goto papan 4 buah, dan goto kayu 6 buah.

\section{Tempat penampungan}

Tempat penampungan berupa kolam kecil yang dibuat dengan susunan batu di tepi pantai yang fungsinya menampung ikan hasil tangkapan sementara agar kualitas ikan dapat dipertahankan.

\section{Proses penangkapan ikan}

Lokasi pemasangan lampu untuk mengumpulkan ikan lema Teluk Mayalibit dibagi menjadi dua wilayah. Lokasi nelayan Kampung Warsamdin dari pintu masuk Teluk Mayalibit sampai Tanjung Wesiam. Sedangkan lokasi nelayan Kampung Lopintol dari ujung Tanjung Wesiam sampai Pulau Tabako.

Proses penangkapan ikan kembung dengan serok ini mengikuti tahapan sebagai berikut:

1) Tahap persiapan

Pada tahap ini, nelayan sekitar pukul 17.00 mempersiapkan segala perlengkapan untuk operasi penangkapan seperti: alat tangkap serok, tali temali, lampu petromaks, dayung dan bekal.

2) Tahapan menuju daerah penangkapan ikan (fishing ground)

Setelah segala perlengkapan operasi sudah siap diatur di atas perahu, lampu petromaks dinyalakan, kemudian nelayan bergerak ke daerah penangkapan dengan waktu tempuh kira-kira 30 menit dari pantai.

3) Setibanya di lokasi penangkapan, perahu mengapung/menghanyut sampai ikan berkumpul di bawah cahaya lampu.

4) Pada saatgerombolan ikan telah cukup berkumpul, maka lampu petromaks diberi sarung agar ikan lebih terkonsentrasi dibawah lampu.

5) Apabila terlihat ikan bermain atau muncul di depan perahu, maka kurung-kurung didorong ke depan agar cahaya lampu lebih terang dan siap ikan digiring ketempat penangkapan.

6) Setelah ikan cukup terkonsentrasi dan tenang, maka nelayan mengerakan perahu perlahan-lahan menuju labuhan (goto) sebagai tempat pengambilan hasil tangkapan. 
7) Sesampainya di daerahgoto, lampu diredupkan sehingga ikan-ikan lebih konsentrasi; dan pada saat itulah serok di turunkan untuk mengambil ikan hasil tangkapan.

\section{Hasil tangkapan}

Selama penelitian dilakukan 14 kali operasi penangkapan ikan lema dengan total hasil tangkapan sebanyak 12.516 ekor. Hasil terbanyak pada trip ke 9, kemudian diikuti oleh trip ke 7 dan trip ke 6 seperti disajikan pada Tabel 1 dan Gbr. 1.

Ukuran panjang garpu (fork length) ikan kembung

Pada setiap operasi penangkapan diambil 20 ekor ikan untuk pengukuran panjang garpu (FL) dan berat $(\mathrm{g})$ ikan. Total ikan yang diukur sebanyak 280 ekor.Panjang garpu rata-rata $22,1 \mathrm{~cm}$; panjang maksimum 23,6 cm; panjang minimum $20,1 \mathrm{~cm}$. Sedangkan berat ikan rata-rata $252 \mathrm{~g}$; berat maksimum $310 \mathrm{~g}$ dan berat minimum $200 \mathrm{~g}$. Frekuensi panjang hasil tangkapan dibagi dalam 4 kelas seperti disajikan dalam Tabel 2 dan Gbr. 2.
Tabel 1. Jumlah hasil tangkapan selama 14 trip penangkapan

\begin{tabular}{cc}
\hline Trip & Hasil Tangkapan \\
\hline 1 & 110 \\
2 & 330 \\
3 & 732 \\
4 & 337 \\
5 & 906 \\
6 & 1.505 \\
7 & 1.522 \\
8 & 800 \\
9 & 3.229 \\
10 & 419 \\
11 & 1.200 \\
12 & 680 \\
13 & 153 \\
14 & 593 \\
\hline Jumlah & 12.516 \\
\hline
\end{tabular}

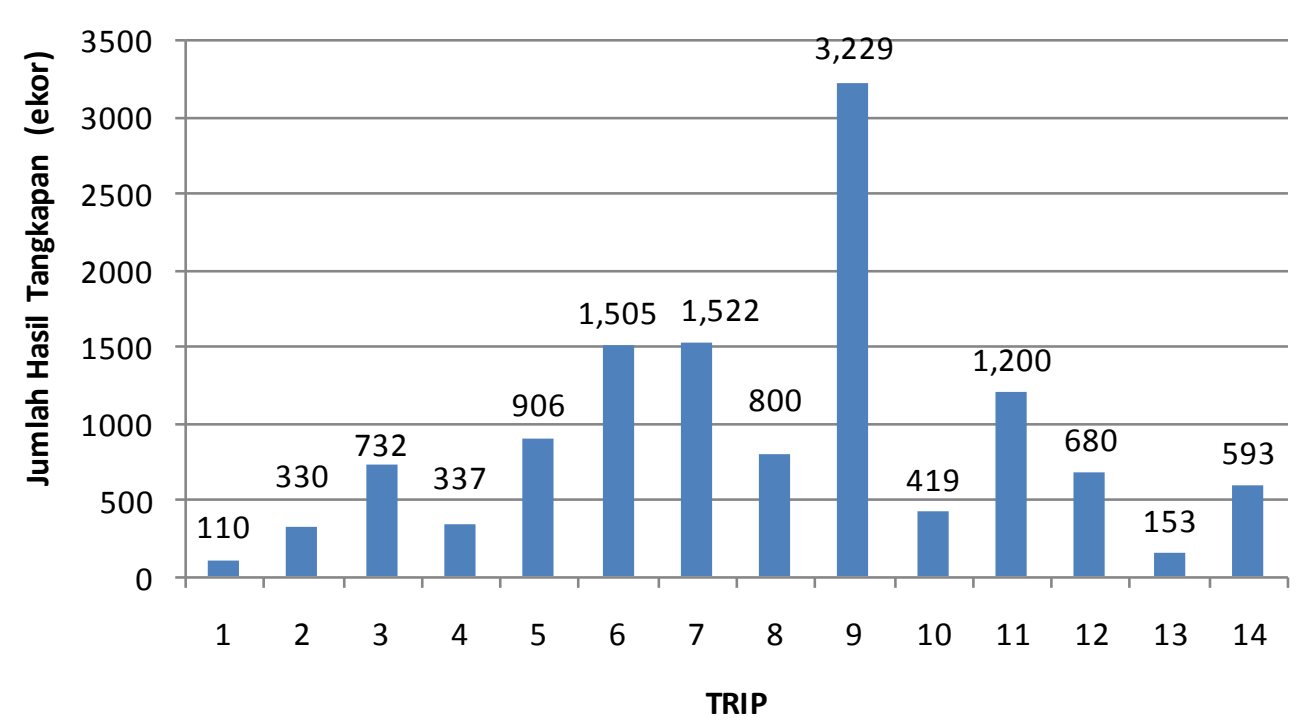

Gambar 1. Sebaran hasil tangkapan selama 14 trip

Tabel 2. Kelas panjang garpu ikan kembung dan jumlahnya

\begin{tabular}{ccc}
\hline Kelas ukuran panjang (FL) & Jumlah (ekor) & Prosentase (\%) \\
\hline $20,0-20,9$ & 20 & 7,14 \\
$21,0-21,9$ & 107 & 38,21 \\
$22,0-22,9$ & 41 & 14,64 \\
$23,0-23,9$ & 112 & 40,00 \\
\hline Jumlah & 280 & 100,00 \\
\hline
\end{tabular}




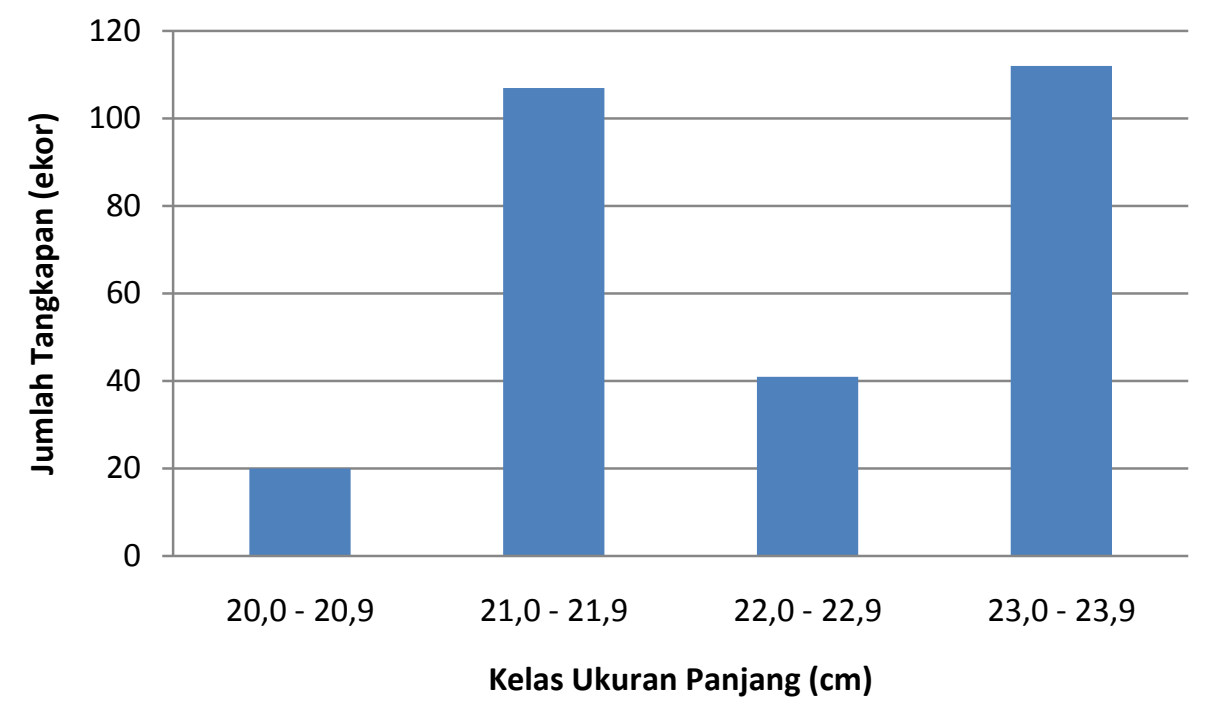

Gambar 2. Frekuensi ukuran panjang garpu ikan kembung

Tabel 2 dan Gbr. 2 menunjukkan bahwa komposisi ukuran panjang ikan kembung yang tertangkap berkisar antara 20-23,9 cm. Ukuran pertama kali matang gonad ikan kembung di Laut Jawa dan perairan India dicapai pada panjang cagak 19,2 cm untuk jantan dan 20,4 cm untuk betina (Nurhakim, 1993; Musbir, et al., 2006). Jadi ikan kembung (lema) yang ditangkap oleh nelayan Warsamdin dan Lopintol adalah ikan yang diduga sudah pernah melakukan pemijahan minimal satu kali dan bahkan sudah yang kedua kalinya. Sehingga dari sisi pengelolaan dan keberlanjutan perikanan lobe merupakan salah satu sebagai perikanan yang ramah lingkungan dan berkelanjutan.

\section{KESIMPULAN}

Kearifan lokal masyarakat Kampung Warsamdin dan Lopintol merupakan pandangan hidup dan ilmu pengetahuan serta berbagai strategi kehidupan yang berwujud aktivitas yang dilakukan oleh masyarakat lokal dalam menjawab berbagai masalah dalam pemenuhan kebutuhan.
Jumlah goto yang ada di Kampung Warsamdin sebanyak 24 buah, sedangkan di Kampung Lopintol sebanyak 44 buah. Jenis goto yang berhasil diidentifikasi, yaitu goto batu sebanyak 14 buah, goto kayu sebanyak 6 buah, dan goto papan sebanyak 4 buah. Dari sampel sebanyak 280 ekor diperoleh 4 kelas panjang baku (FL) yang dominasi oleh kelas panjang 23,0-23,9 cm sebanyak 109 ekor $(39,93 \%)$, dan kisaran panjang 21,0-21,9 cm sebanyak 103 ekor (37,73\%). ukuran ikan lema yang tertangkap sudah pernah melakukan satu kali reproduksi dan bahkan sudah yang kedua kalinya.

\section{DAFTAR PUSTAKA}

Syafaat, R. 2008. Kearifan lokal pada masyarakat adat di Indonesia. Jurnal Publica IV(1): 8-15.

Nasir, M. 1999. Metode Penelitian. Edisi ke-4. Ghalia Indonesia, Jakarta.

Nurhakim, S. 1993. Beberapa aspek reproduksi ikan banyar (Rastrelliger kanagurta) di perairan Laut Jawa. JPPL 81: 8-20.

Musbir, et al, 2006. Pendugaan ukuran pertama kali matang gonad ikan Kembung kanagurta diperairan laut Flores. Sulawesi Selatan. Jurnal Sain \& Teknologi 1(1): 19-26. 